\title{
How to Conference
}

\section{Kimberly Turner', Christina Boyes², Elizabeth Bennion, James Newman ${ }^{4}$}

\section{Introduction}

You may never have attended a conference, but as your department approaches abstract submission deadlines for APSA, MPSA, or another major conference, you can feel the tension in the air. How do you know your work is ready? What happens at conferences and how do you network while there? How do you budget for conferences? What types of conferences exist? In this chapter, we answer these questions and help you navigate the hidden curriculum, find your community, and get the most out of your first political science academic conferences.

Terms like "workshops," "panels," "sessions," "roundtables," "posters," and "section meetings" can confuse first-time attendees. Workshops may be held before, during, or after the main conference and are focused on predetermined topics. They offer an opportunity to get to know other scholars who share your specific research interests. Panels and sessions both refer to the main portion of conferences, within which presenters give brief talks and receive feedback from the audience. In some conferences, discussants are assigned to offer constructive criticism on each presented paper. Roundtables offer participants the chance to ask expert input on a topic. Some roundtables are focused on professionalization while others center on a given topic or may address specific scholarly works. Posters provide presenters an opportunity to talk about their projects in greater depth than presentations allow.

\footnotetext{
${ }^{1}$ International Security Program Postdoctoral Fellow, Belfer Center, Harvard Kennedy School, Harvard University

${ }^{2}$ Assistant Professor (Profesora Titular), Division of International Studies (DEI), Centro de Investigacion y Docencia Economicas (CIDE)

${ }^{3}$ Chancellor's Professor of Political Science, Indiana University South Bend

${ }^{4}$ Associate Professor, Southeast Missouri State University
} 
Beyond providing opportunities to share your work, conferences offer additional networking opportunities such as happy hours and receptions. Additional professional advancement opportunities exist at conference vendor or exhibitor tables and recruitment events.

\section{Are You Ready to Conference?}

Conference attendance and presentation of research are viewed as one of the most important activities for scholars. Conferences allow you to develop an identity in the discipline while gaining awareness of how your research fits into the larger body of literature. They also allow you to connect with scholars and mentors.

Ask yourself what conference is right for your work. If you are in your first year of graduate school, consider presenting at a state or regional conference. Master's level work is often presented at state conferences. Some state and national conferences develop panels composed exclusively of students without a Ph.D.

Do not overlook interdisciplinary conferences such as the Western Social Science Association. These conferences may have sections devoted to subfields related to your research. Presenting findings from your dissertation or other major research project is encouraged at most interdisciplinary and regional conferences.

Networking allows you to engage with scholars at all levels, offers access to resources, and provides you with critical advice about grants, workshops, and writing groups. It also gives you an opportunity to promote your research. This is particularly important for students from less prestigious institutions or who have limited access to institutional resources.

Network vertically and horizontally. Develop a wide and deep network of fellow graduate students who will be your future colleagues, editors, and reviewers. This network can act as a conduit into new streams of vertical networking; you now have access to their advisors 
and mentors as well. These friendships and collaborations can last decades; do not neglect them to seek out senior scholars who will soon retire or those at top universities. The majority of the professoriate is located outside of the small set of elite institutions. Avoid the inefficient and counterproductive networking tactic colloquially known as "name badging." This is when individuals initiate (or suspend) networking according to institutional prestige. Not only is it rude to immediately glance at someone's name badge to determine whether to continue a conversation, these are your current and future colleagues. This disrespectful practice can have major downstream consequences, as academics have long memories.

Assistant professors can offer crucial advice about the job market and the transition to the professoriate. They are integrated into whisper networks and often generous with inside information on salaries, toxic work environments, and living conditions.

Associate professors often have students and may have less bandwidth to take on external mentees. Still, watch Twitter prior to conferences, as many associate professors will hold open coffee hours. Many will offer to look over resumes and job files and offer market advice. Take advantage of these offers and meet as many scholars as possible. Many postdoctoral fellowships require advisory supervision at the associate level, so it is important that associate faculty know who you are and have heard of your scholarship.

Many full professors are often busy at conferences and have limited time for their own students, much less external students. In order to maximize the likelihood of successfully scheduling a meeting with a senior scholar, set up a coffee meeting weeks in advance. At the meeting, have a short agenda scripted for yourself of what you wish to discuss with them. Prepare to be interrupted as people they know come up to them. Be direct and make it clear how 
your research is connected to theirs in a deep substantive way, what new angle you are working, and why you want them to know about it.

\section{Budgeting}

Funding is a major conference issue, particularly for under-resourced students and those who have caretaking responsibilities. Graduate student stipends can make it difficult to attend conferences. Even when university grants or travel funding are available, they are often provided via reimbursement. Major conferences often offer highly competitive travel grants for attendees. These are worth applying for, but there are limited funds and larger conferences tend to be more expensive than smaller, regional conferences. There are, however, ways to attend conferences in your field without spending too much (if anything). Increasingly, conferences offer online options, too, though networking opportunities may be more limited in the online environment.

If a regional or topic-specific conference such as the Ostrom WOW, Peace Science, or IPES is held at your university, student volunteers may be needed and receive free or discounted registration for their help. Additionally, these conferences may be easier for graduate students with caretaking responsibilities to attend without needing to make special arrangements. Some larger conferences may also offer discounted or free registration to students who assist with the conference preparations.

\section{Why Does It Matter?}

Conferencing provides crucial opportunities for funding, research collaborations, and professional service. Additionally, conferences expose attendees to new and useful developments in the field and offer skill development and networking opportunities for attendees (Oester et al 2017). Conferences provide a network of people who can offer advice and support during your 
academic journey and serve as reviewers or recommenders for later promotion decisions and grant proposals. First-generation graduate students, BIPOC, and women often face conference barriers and confidence gaps that reduce their likelihood to actively network. Conferences provide an opportunity to level the playing field by expanding your academic community and finding mentors (O'Brien 2020). Networking and being mentored, in turn, helps career advancement (Argyle and Mendelberg 2020).

\section{Hidden Curriculum}

Despite having navigated the underlying culture and norms at your home institution, you may be unfamiliar with the norms, channels, and access points of political science. Lack of transparency and information regarding prestigious workshops, mini-conferences, and inter-institutional seminars reduce the competitiveness of students without access to elite networks and channels. Networking can help compensate.

Speaking to other students about their activities and discussing new opportunities with faculty provides crucial information on opportunities and potential supporters, advisors, and advocates for your participation in new venues. Participation in these endeavors can be careerchanging and provide a crucial platform for your work. For female-identifying and BIPOC attendees, these opportunities can be impossible to break into without the right "access," which is often provided via your social network. This is compounded for many marginalized and racialized attendees if they are first-generation, and thus, do not have the a priori networks and knowledge of their classmates and colleagues.

The ability to break into more "closed" conferences, such as Polmeth, is easier if you have a particular set of credentials. Attendance at ICPSR, EITM, or IQMR signals your skills and provides you with networks embedded in conference leadership. While some schools 
provide their students with information and funding on workshops, many do not. Information booths at conferences often inform students about available participation and scholarship opportunities.

\section{What Should You Do?}

If you have a course paper that has received feedback from the course's instructor and you addressed the feedback, the paper is likely ready for submission. While the paper may not be accepted at a national conference, it may be appropriate for state or regional conferences. Many states host annual conferences with lower registration and travel costs. As a doctoral student, a state or local conference is an obvious place to start, due to the high acceptance rate and reduced travel costs. Notably, some smaller state, local, and regional conferences are also free.

As you gain experience, presenting papers at a regional conference (e.g. MPSA) is a good next step. You may want to present at a conference focusing on a particular subfield (e.g. State Politics and Policy.) Your advisor should help you evaluate the appropriateness of a conference for your work.

While dissertating, aim to present your findings at national conferences. Doing so gets your project noticed and gives you job talk practice. Furthermore, papers presented at conferences such as APSA also have a significantly higher likelihood of being cited (Lopez de Leon and McQuillen 2020).

Graduate students, junior scholars, and underrepresented scholars often face additional access barriers to conferences that are financial and non-financial in nature. Sections will often sponsor student travel and/or membership fees. Conferences are increasingly providing nursing stations and scholarships for childcare services. Take advantage of the subsidized graduate student hotel rates. This block of hotel rooms often sells out on the first day, so make sure to 
consistently check when they become available. If you miss out, check Twitter for fellow grad students seeking roommates for the conference.

Dining out is expensive. Many publishers hold morning breakfast surveys or focus groups, offering a continental breakfast and easy cash. Conferences often host coffee barsMPSA is famous for its lavish coffee bar. Receptions are an easy way to eat dinner. Most receptions are open to all attendees, unless otherwise specified. If you made a friend at a university that is sponsoring a reception, text them you will meet them there. You can eat dinner, meet up with new friends, and network all in a single stroke.

Clothing is often a barrier for students with limited funds. Don't forget your university career closet! Also, on Twitter, there are often clothing swaps prior to a large conference. Traditional costs of conferencing, such as poster printing and business cards, have become obsolete. Your Twitter handle does more heavy lifting than a business card, and e-posters make the costly poster print no longer necessary.

Non-financial barriers to access also exist. Unfriendly environments, a poor sense of community, and even differential panel/poster acceptance can hinder underrepresented scholars. All of these issues can, to a limited extent, be mitigated via networking. Finding your "group," your set of friends/collaborators/mentors can provide a sense of belonging, ground you in the discipline, and provide clear avenues of mentorship, publication, and career opportunities.

\section{Networking Opportunities}

Networking is a skill you need to hone. Traditional networking still exists, but more modern and casual events are increasing in popularity. In this section, we discuss formal and informal networking at political science conferences. 
Conferences vary in the types of networking opportunities they provide, but all offer opportunities for attendees to become acquainted. Before the conference, strategically consider where and how you will spend your time. Review the program carefully. Highlight the sessions you need to see for your research and those you would like to see to support your colleagues and friends. Contact people you met online who you would be interested in meeting face-to-face and find out where and when they will be presenting.

Much of the conference networking takes place at receptions, in the hallways and lobby of the hotel, and in section meetings. Additionally, sponsored receptions are thrown by publishers, think tanks, organizations, association sections, working groups, and university departments for networking. There are national and regional conferences specifically tailored to BIPOC, such as the National Conference of Black Political Scientists (NCOBPS), and the Politics of Immigration, Race, and Ethnicity Consortium (PRIEC). One example of networking with publishers is the book fair at APSA's Annual Meeting. This extensive book fair exposes you to texts and other materials you may choose to use in your courses. The fair will provide you information about appropriate outlets for your research. This type of interaction with publishers is rare outside of a book fair. Additionally, larger conferences often include sections for various identity groups. Sectional business meetings and receptions can offer graduate students access to new sources of friendships, collaboration, and mentorship.

Once you have a good idea of your conference schedule, look at the social events. For smaller conferences, meals and happy hours may be group events that everyone attends. Join in, have fun, and mingle! If you are shy, remember that you are attending the conference because you and the other attendees are passionate about at least one thing in common-your research areas. 
Receptions can be scary, especially at large conferences such as APSA or MPSA. Take advantage of first-timers' receptions. At MPSA, 5-7 graduate students are put at a table with a "host," a faculty member or senior graduate student very familiar with the conference, hotel, and city. It is a more relaxed, small-scale opportunity to meet other graduate students from around the world, socialize, and mingle. Large-scale receptions such as the President's or final reception offer more scholars to mingle with, but it helps to pre-arrange a reception partner.

Note that conferences act as the main social mechanism in political science. Conferences are where faculty and students have a chance to catch up with friends. Thus, they can be a difficult environment to make new friends. As the receptions often take place at the end of the conference, you have the time to make new friends with whom you can meet at the receptions.

Networking often occurs in the hotel lobby and in the hallways before and after panels. Even occasionally in the elevator! It is useful to get to a panel early: seating can be limited and a surprising amount of glad-handing is done while panelists situate themselves.

Once panels end, they often spill out into the hallways as audience members ask panelists questions. Panelists want people to engage with their work and are often happy to discuss their work in more detail after panels if they have time. If a panelist is in the hallway holding court, join in. Listen, ask questions, get their information, and follow up. This is an excellent way to identify scholarship and scholars that you wish to engage with and is a low-cost manner of networking.

At the panels you attend, do you repeatedly see some faces? Introduce yourself and ask their thoughts on a few of the panels you both attended. You likely share research interests. The time before and after panels is ideal for this type of casual networking. 
Do not forget the exhibitor hall! It is a great place to get swag, but also to network with representatives from programs like ICPSR and publishers. If your dissertation is in book format, it is never too early to begin asking questions about what publishers need and expect when transforming a dissertation into a book. Publishers also often have opportunities for early career scholars to conduct paid surveys, review textbooks, or contribute to test banks. A working relationship with a publisher can provide you with information, and potentially cash.

Section meetings are an excellent and under-utilized networking channel. Most graduate students assume section meetings are closed to them and offer little utility. Not true! Section business meetings are where new policies and programs are set for the sections you belong to or present panels on. Besides agenda setting, sections often give awards and offer travel scholarships for conferences. Few graduate students attend these meetings, but they can be useful spaces to introduce yourself to senior scholars you otherwise would have difficulty meeting.

If meals are not prescheduled, look for opportunities to join lunches, dinners, or happy hours for your sections or groups. In addition to providing networking opportunities, you can often save a little money on food by attending and may hear about opportunities to apply for grants, awards, or funds that may be section or group specific.

Organizations hold receptions to seek out new graduate student members. These organizations often hold lucrative fellowship and travel scholarship opportunities and conduct resume and writing group forums. If you plan to go the alt-ac route, meeting recruiters and leaders of these organizations is very useful. Perhaps you desire to go the publishing route. Use conferences to seek out new employment rather than publishing opportunities. For those interested in agency analyst positions, government agencies still recruit at some conferences, as well. 


\section{New Ways to Network}

We discussed traditional networking in the preceding section. However, networking has evolved with the growth and popularity of political science Twitter. Hashtags such as \#poliscitweets and \#PSJMinfo are often the first sources of information on new conferences, journals, workshops, and jobs. Twitter is also a key community space during conferences. Graduate students and junior faculty often put out a call for hangouts, coffee meetups, knitting circles, or D\&D meetups using Twitter. Informal meetups are an excellent way to grow your social and scholarly network. Informal meals and dine arounds can also be a great way to network, as can grabbing a coffee with someone who attended a panel with you. Most conference attendees have networking and sharing their work in mind.

Although networking can initially feel awkward, you share a common goal and interests. Do not be afraid to DM someone posting about a meetup, even if you do not follow one another. The poster's intent is to meet new friends! Perhaps you want to attend a reception, but it feels too intimidating to do on your own. In late afternoon, Twitter is often awash with "who is attending $\mathrm{X}$ reception?" posts. These posts make excellent ways to attend with and meet your fellow scholars (and you have their profile pic to help limit awkward introductions).

\section{Caretaker Networking}

If you are concerned about managing caretaking and conference responsibilities, keep in mind that many larger conferences offer childcare on site. Even if you cannot attend multiple meals or conference events, make an effort to attend at least one. Also inquire if family members are welcome at events. Often, for smaller conferences, family members are welcome at meals and happy hours. 


\section{What Not to Do at Conferences}

In addition to knowing what you should do, there are also some things to avoid at conferences. Do not...

- ... ignore instructions from session chairs.

- ... become defensive when listening to suggestions from the discussant.

- ... promise more than you can deliver.

Make sure that your proposed project fits your timeline for completion. It is okay to submit a work-in-progress that is part of a larger project, but do not promise a discussion of findings if you may still be collecting data when the conference date arrives. Similarly, volunteer for service roles (e.g. discussant, chair, roundtable participant), but try not to accept any assignments that you cannot fulfill.

Only participate in post-panel Q\&As with constructive comments. The goal is to help panelists improve their work, not to show others in the room how many holes you can poke in the theory, research design, or data.

Avoid being rude or disrespectful to people from any rank or institution. Be the colleague people want to work with! You never know who your future research collaborator, grant/award committee chair, or hiring manager might be.

Be kind to yourself as you navigate your first conferences. Do not overthink awkward interactions or unpleasant experiences; not every conference is the same and persistently engaging in conferences can be highly rewarding. Such large-scale gatherings will exhibit the very best and worst characteristics of our discipline. Stay encouraged and positive about your work and yourself as a person and scholar. The next interaction may be life changing. We often meet our closest friends, collaborators, and occasionally partners at these events. 
If you feel uncomfortable at larger conferences, take advantage of smaller ones. If smaller conferences are more difficult for you, consider larger or medium conferences. Be persistent and you will find a conference community where you feel welcomed.

\section{After the Conference}

Follow-up with people you met to thank them for their time and express your desire to work together in the future (if appropriate). Send hand-written thank you cards after requesting and receiving 1:1 or 2:1 mentoring over a meal. If you discussed collaborating with someone, express your enthusiasm for proceeding and eagerness to learn more about the project timeline and next steps. Save any notes, screenshots, or slides where you can find them easily; you don't want to forget the most relevant tips, information, and ideas you gathered!

\section{References}

1. Argyle, Lisa P., \& Mendelberg, Tali. (2020). Improving Women's Advancement in Political Science: What We Know About What Works. PS: Political Science \& Politics, 53(4), 718-722. doi:10.1017/S1049096520000402

2. Lopez de Leon, Fernanda Leite \& McQuillin, Ben (2020). The Role of Conferences on the Pathway to Academic Impact: Evidence from a natural experiment. The Journal of Human Resources, 55(1), 164-193. URL: http://jhr.uwpress.org/content/55/1/164.full.pdf+html.

3. O'Brien, Diana Z. (2020). NAVIGATING POLITICAL SCIENCE AS A WOMAN. PS: Political Science \& Politics, 53(2), 315-317. doi:10.1017/S1049096519002154 
4. Oester, S., Cigliano, J. A., Hind-Ozan, E. J., \& Parsons, E. C. (2017). Why Conferences Matter-An Illustration from the International Marine Conservation Congress. Frontiers in Marine Science, 4. doi:10.3389/fmars.2017.00257. 